\title{
Visual field survival: the response to timolol therapy in open-angle glaucoma
}

\author{
WILliAM E. SPONSEL, ${ }^{1}$ NEIL L. DALlAS, ${ }^{2}$ AND LAURIE BURBRIDGE ${ }^{2}$ \\ From the 'Department of Ophthalmology, Bristol Eye Hospital, Lower Maudlin Street, Bristol BSI 2LX, \\ and ${ }^{2}$ University of Bristol Computer Centre
}

SUMMARY A simple method for quantifying visual field survival was devised to assess the progress of chronic simple glaucoma in 36 patients treated with timolol maleate over a 3-year period. Routine tonometric monitoring of the intraocular pressure (IOP) was carried out in conjunction with these Goldmann field studies. Statistical analysis revealed that field survival measurement provided a more consistent clinical guide to the progress of glaucoma under treatment than did IOP $(p<0.001)$. Timolol therapy was associated with sustained IOP reductions of $24 \cdot 3-34 \cdot 5 \%$, and $63 \%$ of those treated who were monitored for field survival showed no significant field loss. The observed relationships of IOP to field survival are discussed.

Traditionally the assessment of antiglaucoma therapeutic agents has relied heavily on measurements of intraocular pressure (IOP), even though the susceptibility of individuals to ocular hypertension is highly variable. ${ }^{12}$ Indeed IOP is subject to volatile fluctuation according to diurnal factors, stress, and the treatment-assessment interval. ${ }^{3-5}$ Noncompliance with treatment is a factor to be considered, and some patients resume their therapy a few days or even hours before a clinical assessment, thus giving a false sense of control. Since the aim of treatment is to prevent loss of visual field, any definitive assessment of therapeutic benefit should logically be based on field survival.

In the present study visual field survival has been quantified from Goldmann perimetry data. The effectiveness of timolol maleate in the treatment of open-angle glaucoma has been assessed both in terms of its hypotensive action and its influence on visual field survival.

\section{Patients and methods}

Thirty-six patients with open-angle glaucoma were studied. Twenty-three cases were newly diagnosed, and 13 were patients whose progress or compatibility with other drugs was unsatisfactory. Nineteen were males (mean age 67.6, SD 10.1 years) and 17 were females (mean age $71 \cdot 9$, SD 9.8 years). Three women

Correspondence to Mr N. L. Dallas. were monocular, leaving a total of 69 eyes under study. Introduction to the trial was gradual, and there was no loss of patients among the study group, although 2 patients had unilateral trabeculectomies during the course of treatment.

A regimen of $0.25 \%$ gutt. timolol twice daily was prescribed to all patients, and periodic IOP measurements were made by applanation tonometry. Visual field assessment was carried out by routine Goldmann perimetry, with either the I4e or II4e isoptre being used consistently for each eye. Quantitative approximations of total field area were obtained from the Goldmann traces by simply compiling the sums of the lengths of effective visual area subtended by each of the $2415^{\circ}$ radii on the recording charts (Figs. 1 and 2). Internal field defects were thus subtracted wherever they intersected each radius. Quantitative field data and tonometric IOP data were displayed graphically, and least-squares analysis was performed digitally with an Apple II computerised line-fitting programme.

\section{Results}

The hypotensive responses to timolol therapy in the total study group and the newly diagnosed subgroup are shown in Table 1 . There was no significant difference in IOP response in the 2 groups despite the inclusion of patients experiencing problems with previous forms of therapy in the total study group. The hypotensive effect associated with timolol therapy was sustained throughout the trial period. 


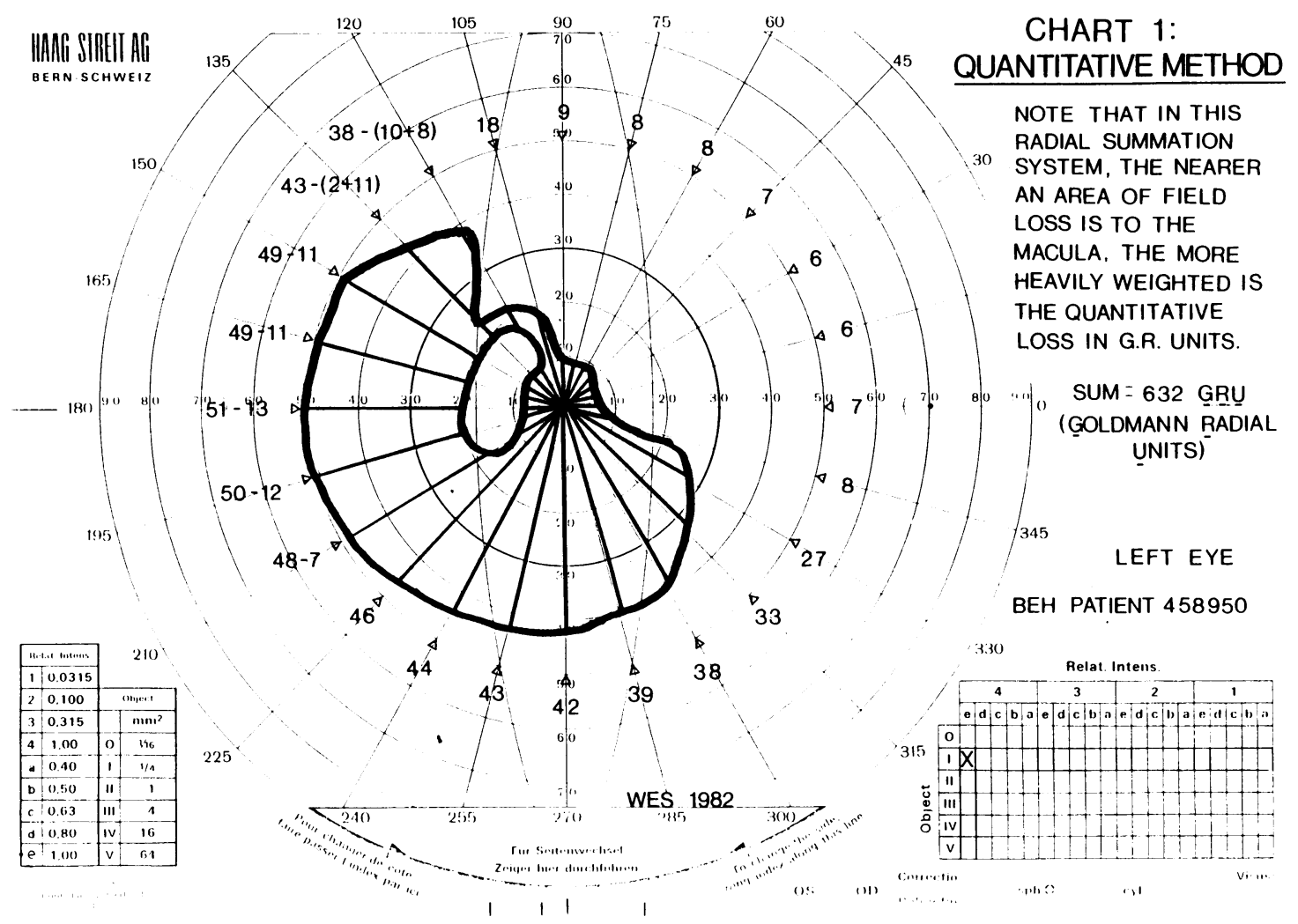

Fig. 1 Radial summation system for approximating visual field survival from routine Goldmann perimetry charts.

An evaluation of IOP and field survival trends in individual patients is shown in Table 2. Comparative. measurements of field survival and IOP were carried out concurrently after the initial sharp hypotensive effect of timolol therapy had settled (i.e., in the 'poststabilisation period'). Statistically, the field data provided a substantially more consistent index of the progress of these treated patients than did IOP measurements. The mean $95 \%$ confidence range for field survival trends in individuals was one-third of that for IOP trends, and the scatter of confidence limits in the population was 3-fold lower using the field data. This ratio of least squares confidence limits is highly significant $(\mathrm{p}<<0 \cdot 001)$.

In Table 3 these findings are correlated to show the relationship of field survival to IOP both in terms of post-stabilisation IOP trends and mean IOP control. Note that only one eye showed a significant IOP increase, and that this was associated with significant field loss. However, a large proportion of the eyes

Table 1 Intraocular pressure changes associated with timolol therapy

\begin{tabular}{|c|c|c|c|c|c|}
\hline & $2-8$ weeks & 6 months & 1 year & 2 years & 3 years \\
\hline \multicolumn{6}{|l|}{ 1. Total study group } \\
\hline No. of eyes & 48 & 51 & 52 & 34 & 8 \\
\hline \multicolumn{6}{|l|}{ Mean IOP $\pm S D$} \\
\hline Pretreatment & $28 \cdot 5 \pm 4 \cdot 2$ & $28 \cdot 6 \pm 4 \cdot 2$ & $27 \cdot 9 \pm 4 \cdot 0$ & $26 \cdot 7 \pm 3 \cdot 2$ & $27 \cdot 5 \pm 2 \cdot 8$ \\
\hline at assessment & $21 \cdot 6 \pm 3 \cdot 3$ & $20 \cdot 9 \pm 3 \cdot 3$ & $20 \cdot 8 \pm 3 \cdot 4$ & $19 \cdot 5 \pm 3 \cdot 3$ & $18 \cdot 0 \pm 4 \cdot 4$ \\
\hline$\%$ reduction IOP & $24 \cdot 3 \%$ & $26 \cdot 8 \%$ & $25.6 \%$ & $26.7 \%$ & $34 \cdot 5 \%$ \\
\hline \multicolumn{6}{|c|}{ 2. Newly diagnosed cases } \\
\hline No. of eyes & 35 & 40 & 40 & 23 & 5 \\
\hline \multicolumn{6}{|l|}{ Mean IOP $\pm S D$} \\
\hline Pretreatment & $29 \cdot 1 \pm 3 \cdot 7$ & $29 \cdot 1 \pm 4 \cdot 2$ & $28 \cdot 4 \pm 3 \cdot 6$ & $27 \cdot 0 \pm 3 \cdot 3$ & $27 \cdot 4 \pm 2 \cdot 9$ \\
\hline at assessment & $22 \cdot() \pm 3 \cdot 1$ & $20 \cdot 8 \pm 3 \cdot 3$ & $20 \cdot 6 \pm 3 \cdot 4$ & $19 \cdot 9 \pm 3 \cdot 2$ & $20 \cdot 0 \pm 1 \cdot 8$ \\
\hline$\%$ reduction IOP & $24 \cdot 4 \%$ & $28 \cdot 5 \%$ & $27 \cdot 5 \%$ & $26.3 \%$ & $27 \cdot 0 \%$ \\
\hline
\end{tabular}




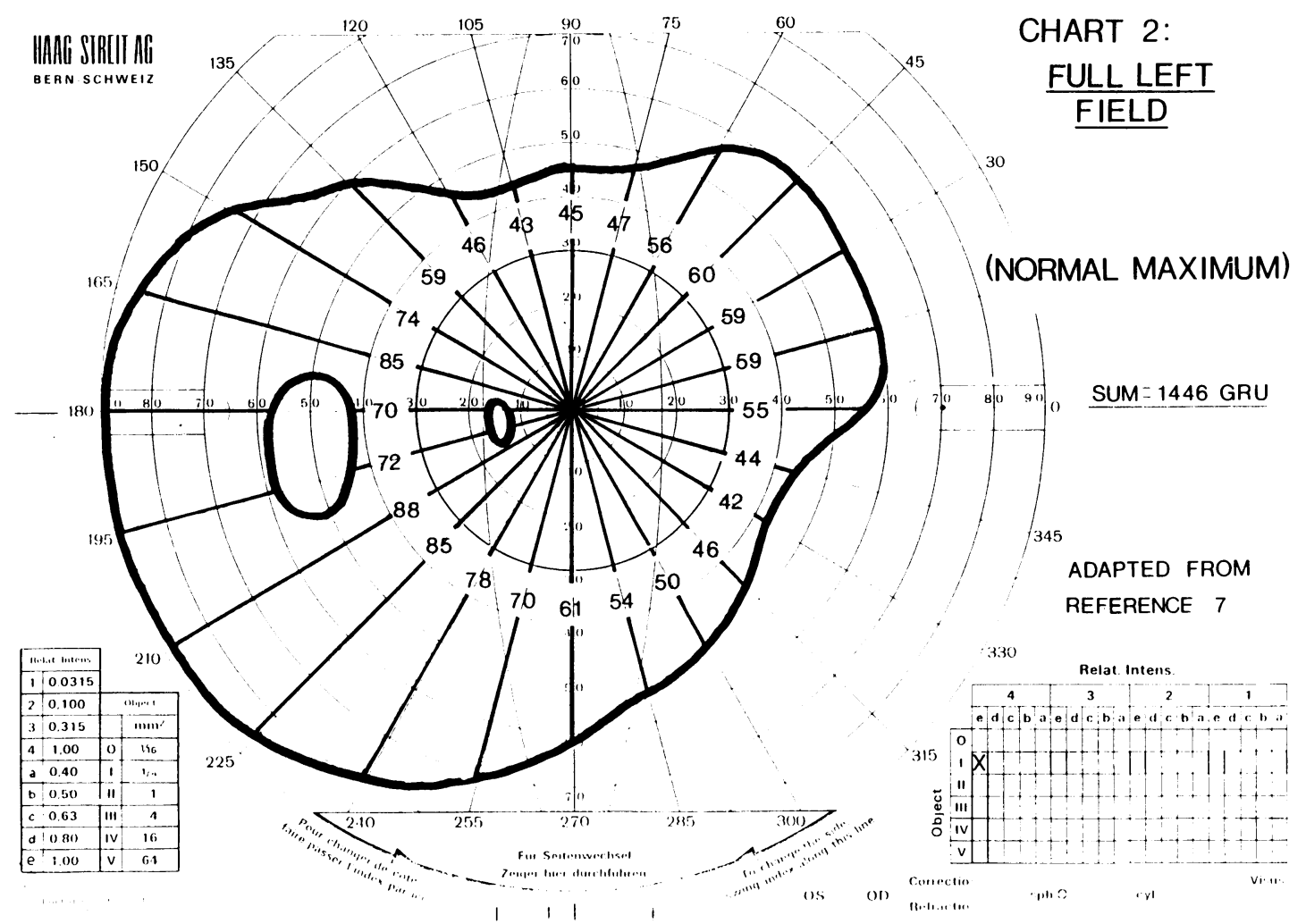

Fig. 2 Radial summation system for approximating visual field survival from routine Goldmann perimetry charts.

showing field loss gave a continued hypotensive response in the post-stabilisation period. The relationship of field loss to mean IOP level was more consistent, with $80 \%$ of eyes persisting with a mean IOP greater than $21 \mathrm{mmHg}$.
Eyes showing no significant field change appeared to be generally better controlled, with stabilisation or gradual diminution of IOP. A similar relationship in IOP trends was observed in those eyes showing significant field gain, but, remarkably, the majority of
Fig. 3 Recorded trends of intraocular pressure and field readings for six individual patients. $R F=$ right field, $L F=$ left field, in Goldmann radial units (defined in text). $L P=$ left pressure, $R P=$ right pressure, intraocular pressure in $\mathrm{mmHg}$. Broken lines along vertical axes indicate approximate normal ranges for $I O P$ and field values in normal healthy subjects. Case 1.

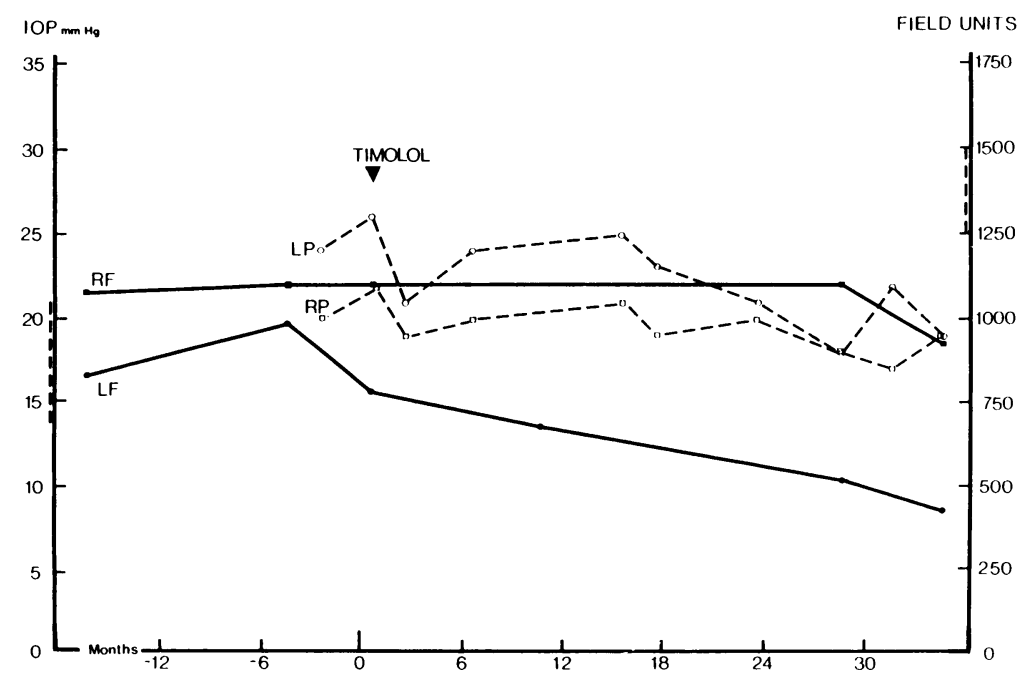


Table 2 Least squares analysis of trends

\begin{tabular}{|c|c|c|c|c|c|c|c|c|c|c|}
\hline \multicolumn{3}{|l|}{ Patient } & \multicolumn{2}{|l|}{ Assessment } & \multicolumn{2}{|c|}{$\begin{array}{l}\text { Y Intercept } \\
\text { (linear starting value) }\end{array}$} & \multicolumn{2}{|l|}{ Slope } & \multicolumn{2}{|c|}{$\begin{array}{l}95 \% \text { Confidence } \\
\text { limits }\end{array}$} \\
\hline Age & Sex & Eye & $\begin{array}{l}\text { Period } \\
\text { (months) }\end{array}$ & $\begin{array}{l}\text { Data } \\
\text { Pts. }\end{array}$ & $\begin{array}{l}I O P \\
(m m H g)\end{array}$ & $\begin{array}{l}\text { Field } \\
(\times 50 G R U)\end{array}$ & $\begin{array}{l}I O P \\
(\text { mmHgI } \\
\text { month })\end{array}$ & $\begin{array}{l}\text { Field } \\
(\times 50 \text { GRUI } \\
\text { month })\end{array}$ & $\begin{array}{l}I O P \\
(+1-)\end{array}$ & $\begin{array}{l}\text { Field } \\
(+/-)\end{array}$ \\
\hline 57 & $\mathbf{M}$ & $\mathrm{R}$ & 12 & 3 & $19 \cdot 00$ & $21 \cdot 43$ & 0.0 & $-0 \cdot 15$ & $8 \cdot 54$ & $1 \cdot 54$ \\
\hline 70 & $\mathbf{M}$ & $\begin{array}{l}\text { L } \\
\text { L }\end{array}$ & $\begin{array}{l}12 \\
27\end{array}$ & $\begin{array}{l}3 \\
3\end{array}$ & $\begin{array}{l}16 \cdot 00 \\
33.37\end{array}$ & $\begin{array}{l}12 \cdot 28 \\
19 \cdot 96\end{array}$ & $\begin{array}{l}+0.64 \\
-0.46\end{array}$ & $\begin{array}{l}-0.34 \\
-0.13\end{array}$ & $\begin{array}{l}1.07 \\
9.87\end{array}$ & $\begin{array}{l}1 \cdot 18 \\
1 \cdot 88\end{array}$ \\
\hline \multirow[t]{2}{*}{58} & $\mathrm{~F}$ & $\mathbf{R}$ & 34 & 4 & $19 \cdot 50$ & $22 \cdot 00$ & -0.03 & -0.03 & $1 \cdot 32$ & $2 \cdot 50$ \\
\hline & & L & 34 & 4 & $23 \cdot 25$ & $16 \cdot 68$ & $-0 \cdot 13$ & $-0 \cdot 20$ & $5 \cdot 03$ & 0.42 \\
\hline 85 & $\mathrm{~F}$ & $\mathrm{~L}$ & 28 & 4 & $20 \cdot 12$ & $21 \cdot 45$ & $-0 \cdot 20$ & +0.02 & $4 \cdot 76$ & 1.06 \\
\hline \multirow{2}{*}{73} & $M$ & $\mathrm{R}$ & 17 & 3 & 15.93 & $6 \cdot 36$ & $-0 \cdot 29$ & 0.0 & $2 \cdot 30$ & 0.77 \\
\hline & & $\mathrm{L}$ & 17 & 3 & $15 \cdot 93$ & $19 \cdot 39$ & -0.29 & $+0 \cdot 15$ & $2 \cdot 30$ & 1.54 \\
\hline \multirow[t]{2}{*}{77} & $M$ & $\mathrm{R}$ & 22 & 3 & $25 \cdot 34$ & $14 \cdot 29$ & $-0 \cdot 17$ & $-0 \cdot 15$ & $3 \cdot 28$ & $2 \cdot 89$ \\
\hline & & $\mathrm{L}$ & 22 & 3 & $25 \cdot 19$ & $20 \cdot 15$ & -0.29 & $+0 \cdot 10$ & 1.83 & 0.69 \\
\hline \multirow[t]{2}{*}{80} & $\mathbf{M}$ & $\mathrm{R}$ & 22 & 4 & $19 \cdot 85$ & $14 \cdot 58$ & -0.04 & $-0 \cdot 18$ & $3 \cdot 68$ & $1 \cdot 33$ \\
\hline & & $\mathrm{L}$ & 22 & 4 & $20 \cdot 30$ & $22 \cdot 34$ & $-0 \cdot 11$ & -0.03 & $1 \cdot 26$ & $1 \cdot 45$ \\
\hline \multirow[t]{2}{*}{51} & $\mathbf{M}$ & $\mathbf{R}$ & 25 & 3 & $24 \cdot 00$ & $20 \cdot 60$ & -0.07 & $+0 \cdot 01$ & 2.57 & 0.04 \\
\hline & & $\mathrm{L}$ & 25 & 3 & $24 \cdot 41$ & $22 \cdot 93$ & $-0 \cdot 08$ & +0.21 & 1.51 & 1.73 \\
\hline 62 & $\mathbf{M}$ & $\mathbf{R}$ & 33 & 5 & $23 \cdot 24$ & $12 \cdot 43$ & $-0 \cdot 26$ & -0.44 & $3 \cdot 13$ & $1 \cdot 39$ \\
\hline \multirow[t]{2}{*}{78} & M & $\mathbf{R}$ & 13 & 3 & $23 \cdot 16$ & $12 \cdot 63$ & -0.52 & $-0 \cdot 29$ & 0.93 & $3 \cdot 60$ \\
\hline & & L & 13 & 3 & 18.67 & $24 \cdot 62$ & $0 \cdot 0$ & $-0 \cdot 26$ & $8 \cdot 84$ & 1.09 \\
\hline 54 & $\mathbf{M}$ & $\mathbf{R}$ & 13 & 3 & $22 \cdot 63$ & $25 \cdot 31$ & $0 \cdot 0$ & -0.32 & $2 \cdot 12$ & 0.79 \\
\hline \multirow[t]{2}{*}{64} & M & $\mathrm{R}$ & 31 & 4 & $18 \cdot 98$ & 16.93 & $-0 \cdot 01$ & $+0 \cdot 14$ & $5 \cdot 84$ & $1 \cdot 34$ \\
\hline & & $\mathrm{L}$ & 31 & 4 & 12.96 & 1.00 & $-0 \cdot 08$ & $0 \cdot 0$ & $3 \cdot 70$ & 0.0 \\
\hline \multirow[t]{2}{*}{82} & $\mathrm{~F}$ & $\mathrm{R}$ & 20 & 3 & $25 \cdot 18$ & $15 \cdot 52$ & $-0 \cdot 21$ & $+0 \cdot 30$ & 3.86 & $1 \cdot 85$ \\
\hline & & $\mathrm{L}$ & 20 & 3 & $25 \cdot 01$ & $20 \cdot 41$ & 0.0 & +0.21 & $9 \cdot 80$ & $2 \cdot 44$ \\
\hline \multirow[t]{2}{*}{57} & $\mathbf{M}$ & $\mathrm{R}$ & 15 & 3 & $20 \cdot 60$ & $24 \cdot 55$ & +0.23 & +0.07 & $1 \cdot 53$ & $0 \cdot 26$ \\
\hline & & $\mathrm{L}$ & 15 & 3 & $24 \cdot 71$ & $27 \cdot 80$ & +0.27 & $-0 \cdot 18$ & $2 \cdot 50$ & 0.02 \\
\hline \multirow[t]{2}{*}{73} & $F$ & $\mathrm{R}$ & 24 & 3 & $23 \cdot 53$ & $16 \cdot 77$ & $-0 \cdot 10$ & $-0 \cdot 17$ & $3 \cdot 25$ & 0.49 \\
\hline & & $\mathrm{L}$ & 24 & 3 & $26 \cdot 34$ & $11 \cdot 30$ & 0.0 & $+0 \cdot 16$ & $4 \cdot 08$ & 0.56 \\
\hline $\begin{array}{l}\text { Mean: } \\
68 \cdot 5\end{array}$ & $\begin{array}{c}11 \mathrm{M} \\
4 \mathrm{~F}\end{array}$ & $\begin{array}{l}13 \mathrm{R} \\
13 \mathrm{~L}\end{array}$ & $22 \cdot 0$ & $3 \cdot 3$ & $21 \cdot 82$ & $17 \cdot 80$ & -0.09 & $-0 \cdot 04$ & $3 \cdot 80$ & $1 \cdot 26$ \\
\hline
\end{tabular}

Twenty-six eyes were assessed for visual field survival on 3 or more occasions following the commencement of timolol therapy. The least squares $95 \%$ confidence limits for linear trends defined by field survival against time are compared with those defined by IOP readings taken on the same dates. Field and IOP data have been normalised within comparable variability ranges such that $1 \mathrm{mmHg}$ IOP equates with 50 Goldmann radial units (GRU) of visual field (see text for quantitation method).

these eyes did not have adequate control of IOP.

The comparative IOP and field data in 17 further patients ( 33 eyes) who had only two post-treatment field assessments were also examined. Of these eyes 5 $(15 \%)$ showed marked field loss and 5 marked field gain (greater than 14 field units per month slope).
Four of the 5 eyes in the group with apparent field loss had inadequate IOP control, but 3 of these eyes nevertheless showed sustained downward IOP trends. The relationship of field gain to mean IOP level was again contradictory, with 3 of the 5 eyes persisting with a mean IOP above $21 \mathrm{mmHg}$.

Table 3 Relationship of field survival to IOP trends and IOP control

\begin{tabular}{|c|c|c|c|c|c|}
\hline \multirow[t]{2}{*}{ Field survival trend } & \multicolumn{3}{|l|}{ IOP trend } & \multicolumn{2}{|c|}{ Mean IOP value } \\
\hline & $\begin{array}{l}\text { Significant } \\
\text { increase }\end{array}$ & $\begin{array}{l}\text { Significant } \\
\text { decrease }\end{array}$ & $\begin{array}{l}\text { No significant } \\
\text { change }\end{array}$ & $\begin{array}{l}\text { Above } \\
21 \mathrm{mmHg}\end{array}$ & $\begin{array}{l}\text { Below } \\
21 \mathrm{mmHg}\end{array}$ \\
\hline Significant field loss (10 eyes) & $1(10 \%)$ & $4(40 \%)$ & $5(50 \%)$ & $8(80 \%)$ & $2(20 \%)$ \\
\hline No significant field change ( 11 eyes) & 0 & $4(36 \%)$ & $7(64 \%)$ & $3(27 \%)$ & $8(73 \%)$ \\
\hline Significant field gain (6 eyes) & 0 & $2(33 \%)$ & $4(67 \%)$ & $4(67 \%)$ & $2(33 \%)$ \\
\hline Totals ( 27 eyes) & $1(4 \%)$ & $10(37 \%)$ & $16(59 \%)$ & $15(56 \%)$ & $12(44 \%)$ \\
\hline
\end{tabular}

Fields and IOP trends analysed by least squares (Table 2) are compared in terms of their slopes. The relationship of mean IOP values to field survival is also provided. IOP or field change is defined as significant when (slope $\times$ period of assessment in months) exceeds $(2 \times 95 \%$ least squares confidence limit). 
Fig. 4 Recorded trends of intraocular pressure and field readings for 6 individual patients. $R F=$ right field, $L F=$ left field, in Goldmann radial units (defined in text). $L P=$ left pressure, $R P=$ right pressure, intraocular pressure in $\mathrm{mmHg}$. Broken lines along vertical axes indicate approximate normal ranges for IOP and field values in normal healthy subjects. Case 2.

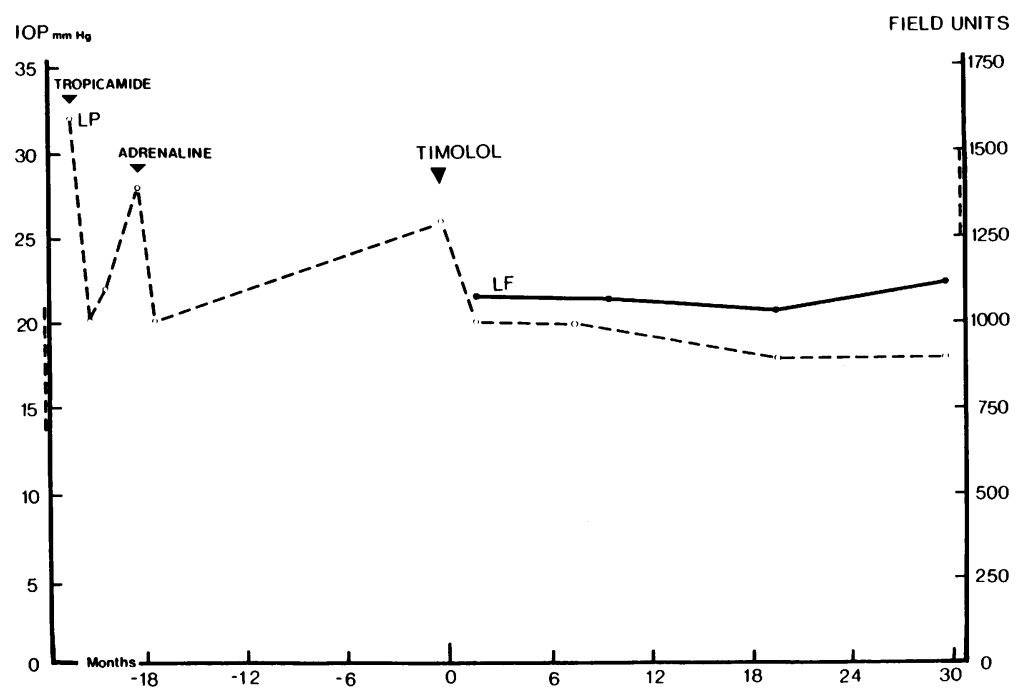

achieved with timolol with the transient effects of 2 previous treatments with mydriatic agents in a monocular patient. This patient also had a history of adverse reaction to pilocarpine. The field response was a typical example of the stabilisation associated with IOP control.

Figs. 5 and 6 are both examples of field gain associated with erratic and frequently hypertensive IOP readings. Fig. 5 shows the progress of a 64 -yearold man with a 10-year history of chronic simple glaucoma whose left field had degenerated to its macula during previous treatments with mydriatic agents. Despite an unusual upsurge in IOP following the initiation of timolol therapy, however, progressive
Fig. 5 Recorded trends of intraocular pressure and field readings for 6 individual patients. $R F=$ right field, $L F=$ left field, in Goldmann radial units (defined in text). $L P=$ left pressure, $R P=$ right pressure, intraocular pressure in $\mathrm{mmHg}$. Broken lines along vertical axes indicate approximate normal ranges for IOP and field values in normal healthy subjects. Case 3.

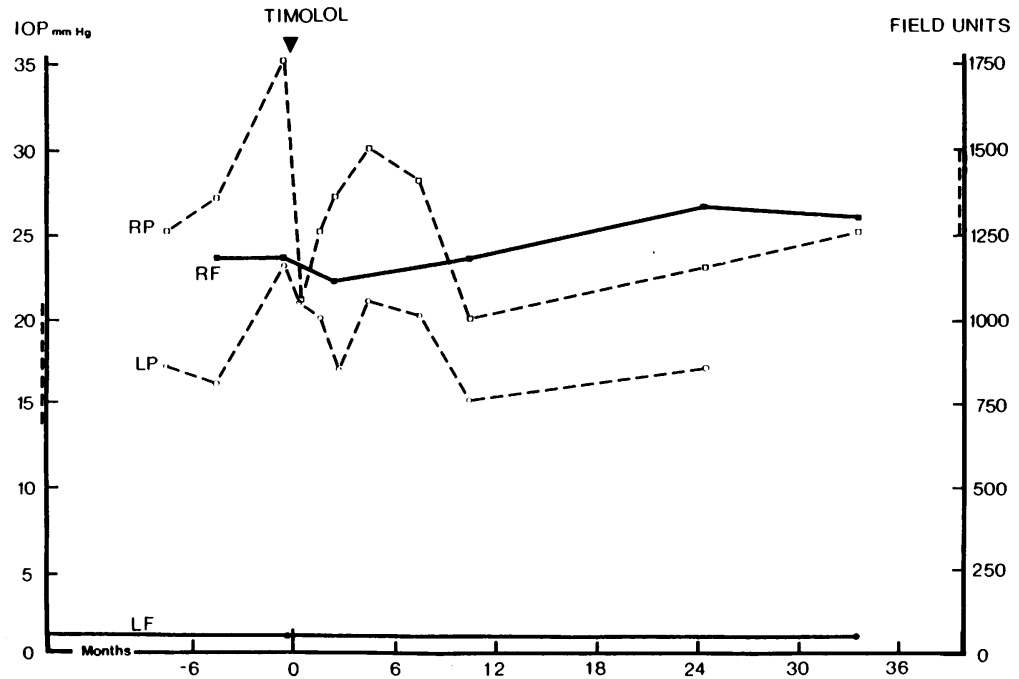




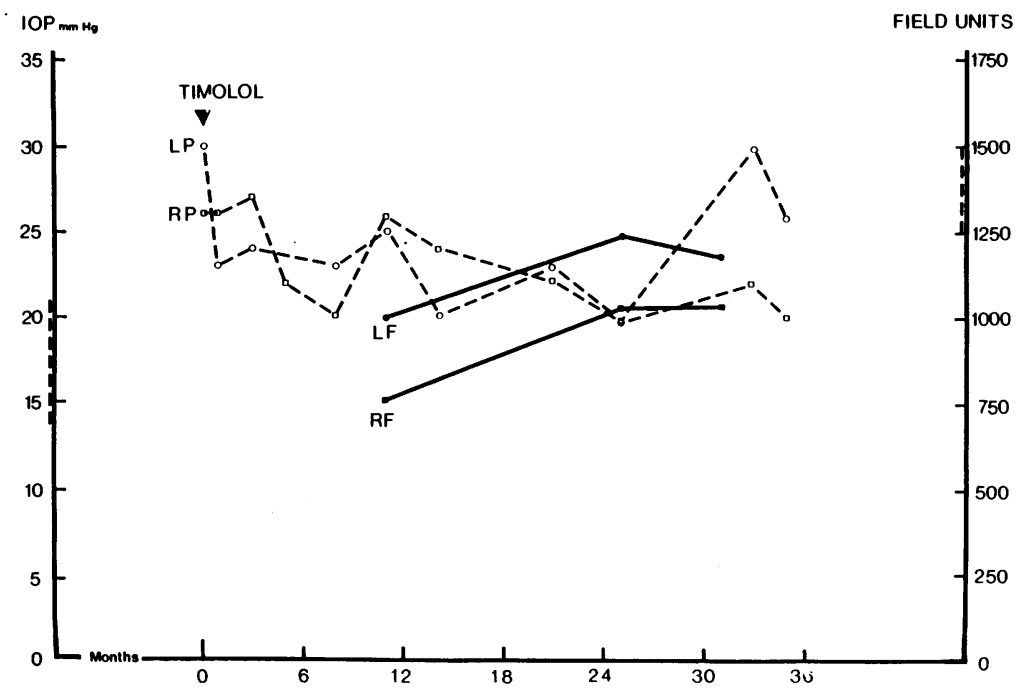

Fig. 6 Recorded trends of intraocular pressure and field readings for 6 individual patients. $R F=$ right field, $L F=$ left field, in Goldmann radial units (defined in text). $L P=$ left pressure, $R P=$ right pressure, intraocular pressure in $\mathrm{mmHg}$. Broken lines along vertical axes indicate approximate normal ranges for IOP and field values in normal healthy subjects. Case 4.

field improvement occurred in the surviving right eye. Fig. 6 provides a further illustration of apparent field improvement in spite of poor IOP control. This patient's final field values in both eyes approached 90\% of those recorded in 1977 when her glaucoma was first diagnosed. Various mydriatic agents had been used prior to her timolol therapy.

Fig. 7 shows the findings from a patient whose continued hypotensive response to abnormally low levels during timolol therapy was nevertheless associated with field stability in both eyes.

Fig. 8 shows the result of trabeculectomy in a patient whose IOP response to timolol was initially hypertensive. Note the striking postoperative improvement in the left eye, while the unoperated right eye showed continued field deterioration in spite of its lower mean IOP level.

\section{Discussion}

There is a natural tendency among clinicians when interpreting perimetry charts to lay special emphasis on the detailed configuration of internal field defects. In the present study we have observed considerable shifts in the scotomal configurations of patients whose total field survival readings remained surprisingly constant. Conversely, we have seen instances where progressive contraction of the peripheral field

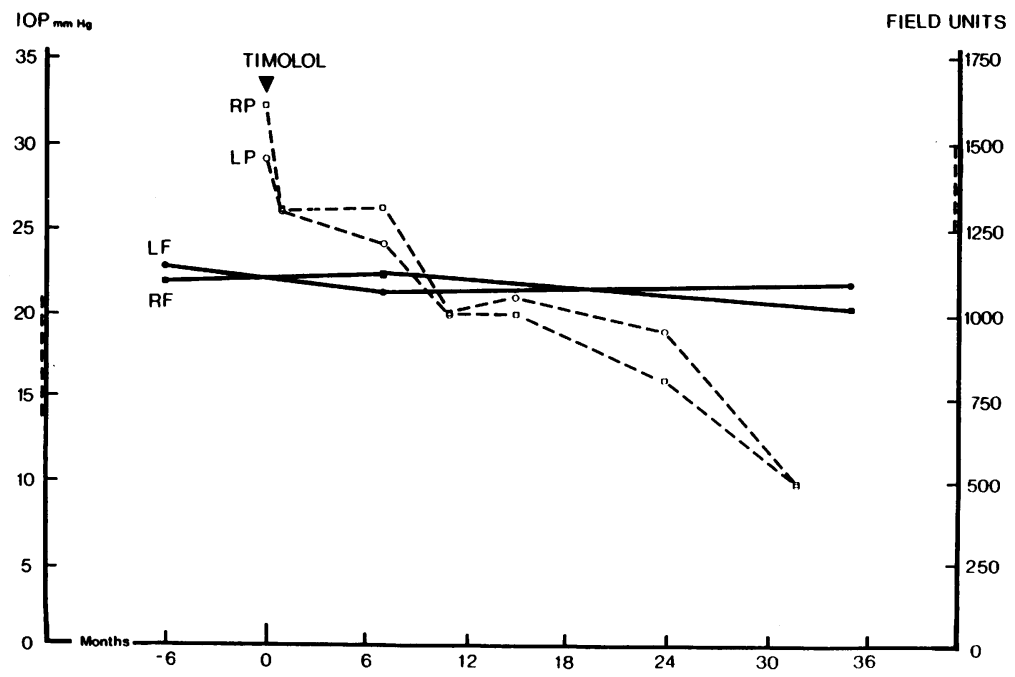

Fig. 7 Recorded trends of intraocular pressure and field readings for 6 individual patients. $R F=$ right field, $L F=$ left field, in Goldmann radial units (defined in text). $L P=$ left pressure, $R P=$ right pressure, intraocular pressure in $\mathrm{mm} \mathrm{Hg}$. Broken lines along vertical axes indicate approximate normal ranges for IOP and field values in normal healthy subjects. Case 5. 
Fig. 8 Recorded trends of intraocular pressure and field readings for 6 individual patients. $R F=$ right field, $L F=$ left field, in Goldmann radial units (defined in text). $L P=$ left pressure, $R P=$ right pressure, intraocular pressure in $\mathrm{mmHg}$. Broken lines along vertical ranges for IOP and field values in normal healthy subjects. Case 6. axes indicate approximate normal

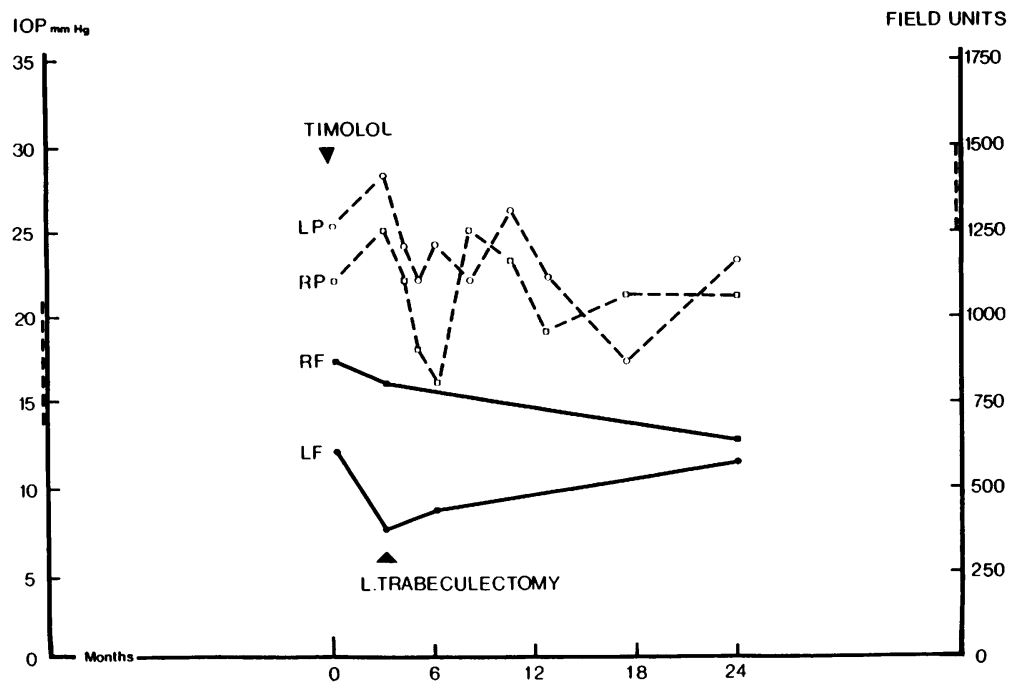

occurred without any major associated internal field defects. Even without such complications lack of time in the outpatient clinic may limit one's ability to assimilate fully all the relevant detail from numerous 2-dimensional field charts scattered throughout a patient's notes. If marked field loss such as that illustrated by Fig. 3 is to be avoided, it is essential that the total field survival readings of all open-angle glaucoma patients should be available routinely. A method for achieving this aim rapidly and inexpensively is described in the appendix below.

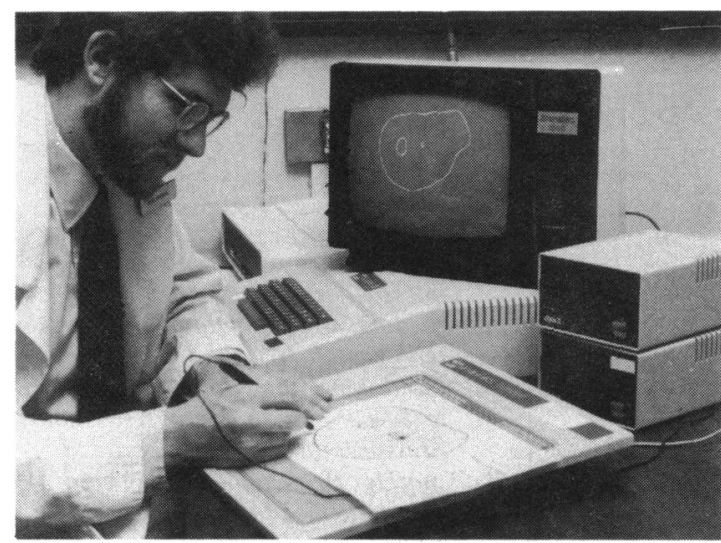

Fig. 9 The Apple II microcomputer with manual graphics tablet as adapted for assessment of standard Goldmann perimetry charts. This straightforward storage, retrieval, and ' analysis system offers practical clinical and research advantages without interfering with established optometric methods.
Appendix: Application of microcomputers to Goldmann perimetry analysis

An important advance in microcomputer design has been the introduction of the manual graphics tablet by the Apple Computer Company. ${ }^{6}$ We have adapted this device to allow the tracing-out of routine Goldmann perimetry plots with an electronic pen so as to provide immediate printouts of total field and scotomal areas (Fig. 9). It should be stressed that this microcomputer is independent of the perimetry apparatus and is capable of storing, analysing, and comparing field information from distant clinics and previous patient records. Thus there is no interference with the established clinical routine of the optometric department. Moreover, the mechanical simplicity and reliability of Goldmann perimetry is preserved, along with the important personal contribution of the professional optometrist.

Any data relevant to an individual patient's case may be readily entered on to the microcomputer memory disc along with the perimetry recordings. Thus tabulations of IOP and field survival such as those shown in Figs. 3-8 could be printed out periodically as required. Information could be retrieved by reference to a variety of parameters (e.g., age, sex, admission date, drug regimen, initial field, or IOP values, etc.), thus greatly facilitating statistical analysis for research purposes. The flexibility of the Apple II computer system would allow for easy updating of patient information, thereby minimising the burden on administrative staff and consultants. Appointment letters could be automatically printed out and addressed according to the date and result of the previous assessment.

The potential of such a system for providing chronological progress reports at a glance has generated considerable interest, and further developments are under way, including a double-blind trial of the effects of timolol and pilocarpine. Ease of use of the system by personnel without computer expertise is a prime objective of this co-operative venture between ophthalmological and computer systems staff. 
We gratefully acknowledge the help of Miss Rosemary Foley, senior orthoptist at Bristol Eye Hospital. Thanks are also due to Dr Alan Hedges for statistical advice.

\section{References}

1 Leydhecker W, Krieglstein GK. Ocular hypertension-glaucoma suspect or incipient glaucoma? Res Clin Forums 1980; 2: 121-8.

2 Smith RJH. Ocular hypertension. Res Clin Forums 1980; 2: 129-31.
3 Kitazawa Y, Horie T. Diurnal variation of intraocular pressure in primary open angle glaucoma. Am J Ophthalmol 1975; 79: 557-66.

4 Norell Staffan E. Compliance with pilocarpine therapy. (1981) Am J Ophthalmol 1981; 92: 727-31.

5 Jones DEP, Norton DA, Davies DJG. The response of primary open angle glaucoma to topical timolol therapy. Res Clin Forums 1980; 2: 179-82.

6 Apple Graphics Tablet Manual. Cupertino: Apple Computer Inc. 1982.

7 Wybar K. Ophthalmology. London: Baillière Tindall, 1979: 322. 